\title{
Human umbilical cord mesenchymal stromal cells in a sandwich approach for osteochondral tissue engineering
}

\author{
Limin Wang1,\#, Liang Zhao2,\#, and Michael S. Detamore, ${ }^{2,}$ \\ ${ }^{1}$ Department of Biomedical Engineering, University of Michigan, Ann Arbor, MI 48109, USA \\ ${ }^{2}$ Department of Chemical and Petroleum Engineering, University of Kansas, Lawrence, KS \\ 66045, USA
}

\section{Abstract}

Cell sources and tissue integration between cartilage and bone regions are critical to successful osteochondral regeneration. In this study, human umbilical cord mesenchymal stromal cells (hUCMSCs), derived from Wharton's jelly, were introduced to the field of osteochondral tissue engineering and a new strategy for osteochondral integration was developed by sandwiching a layer of cells between chondrogenic and osteogenic constructs before suturing them together. Specifically, hUCMSCs were cultured in biodegradable poly-L-lactic acid scaffolds for 3 weeks in either chondrogenic or osteogenic medium to differentiate cells toward cartilage or bone lineages, respectively. A highly concentrated cell solution containing undifferentiated hUCMSCs was pasted onto the surface of the bone layer at week 3 and the two layers were then sutured together to form an osteochondral composite for another 3 week culture period. Chondrogenic and osteogenic differentiation was initiated during the first 3 weeks, as evidenced by the expression of type II collagen and runt-related transcription factor 2 genes, respectively, and continued with the increase of extracellular matrix during the last 3 weeks. Histological and immunohistochemical staining, such as for glycosaminoglycans, type I collagen and calcium, revealed better integration and transition of these matrices between two layers in the composite group containing sandwiched cells compared to other control composites. These results suggest that hUCMSCs may be a suitable cell source for osteochondral regeneration, and the strategy of sandwiching cells between two layers may facilitate scaffold and tissue integration.

\section{Keywords}

umbilical cord; stromal cells; osteochondral tissue engineering; integration

\section{Introduction}

Osteochondral tissue engineering has been proposed as a potential cure for both osteochondral and cartilage defects. The damage of two distinct tissues, bone and cartilage, in osteochondral defects necessitates the regeneration of integrated complex tissues. More recently, osteochondral strategies have been advocated for cartilage repair instead of solely cartilage engineering, due to the difficulty of integrating engineered constructs with the cartilage surrounding the excised cartilage. In contrast, the integration of bone-to-bone fusion is far superior to cartilage-to-cartilage fusion because of the well-known healing

\footnotetext{
Copyright (C) 2010 John Wiley \& Sons, Ltd.

*Correspondence to: Michael S. Detamore, Department of Chemical and Petroleum Engineering, University of Kansas, 4132 Learned Hall, 1530 W 15th Street, Lawrence, KS 66045, USA. detamore@ku.edu.

\#These authors contributed equally to this work and are considered co-first authors.
} 
ability of bone tissues (Grayson et al., 2008). Although osteochondral constructs have been engineered using a variety of biomaterials with different types of cells, the choice of cell sources and osteochondral integration are still major issues for osteochondral tissue engineering.

For a successful osteochondral strategy, it is necessary to adopt a cell source that must be easily isolated and quickly expanded to obtain sufficient cell numbers, has low immune response, and ideally has no donor site morbidity. Mature autologous chondrocytes and osteoblasts are limited by their proliferation ability in vitro and donor site morbidity. Stem cells, such as bone marrow cells and adipose stem cells, offer a feasible alternative to differentiated autologous cells, with the potential to undergo continuous self-renewal and differentiate toward osteogenic and chondrogenic lineages. Recently, human umbilical cord mesenchymal stromal cells (hUCMSCs), derived from the Wharton's jelly of umbilical cords, have been introduced to both cartilage and bone tissue engineering with many advantages over other adult cell sources (Bailey et al., 2007; Wang et al., 2009a, 2009b, 2009c). hUCMSCs are an inexhaustible stem cell source, are easy to isolate without ethical controversies and invasive procedures, are quickly expanded and thus far appear to exhibit a low immune-rejection reaction in vivo (Wang et al., 2004; Sarugaser et al., 2005; Fu et al., 2006; Weiss and Troyer, 2006; Karahuseyinoglu et al., 2007), thus providing an excellent option as a stem cell source for osteochondral tissue engineering. A variety of biomaterials, both natural and synthetic, have been developed for bone and cartilage tissue engineering applications (Ishaug-Riley et al., 1999; Stevens et al., 2004; Richardson et al., 2006; Zwingmann et al., 2007). In this study, poly-L-lactic acid (PLLA) was chosen for the scaffolds, mainly due to its relatively slow degradation rate and excellent biocompatibility. In a previous study (Wang et al., 2009b), hUCMSCs differentiated into osteoblast-like cells in PLLA scaffolds and the scaffolds maintained their original shape during a 6 week in vitro culture period. Therefore, in the current study, hUCMSCs were seeded into PLLA scaffolds separately for osteogenic and chondrogenic differentiation, followed by scaffold integration using a suturing method.

An ideal structure of osteochondral constructs should mimic native osteochondral joints, which possess a seamless transition between bone and cartilage. A traditional way to achieve this goal is to fabricate biphasic composites that have two independent layers to meet the different demands of bone and cartilage regeneration and then integrate them by various techniques, including layering of cartilage- and bone-like regions (Cao et al., 2003; Alhadlaq and Mao, 2003, 2005; Alhadlaq et al., 2004; Malafaya and Reis, 2009; Guo et al., 2009, 2010), painting chondrocytes onto an osteoblast-containing construct (Weng et al., 2001), suturing (Schaefer et al., 2000; Mrosek et al., 2010) or press-fitting (Schaefer et al., 2002; Tuli et al., 2004) the two layers together, use of a fibrin sealant (Gao et al., 2001) to adhere the two, and simply relying on in vivo conditions (Wakitani et al., 1994; Angele et al., 1999). However, these methods did not necessarily lead to solid integration and smooth transition between two layers, possibly due to sparse cells on the interface, consequently resulting in the separation of bone and cartilage (O'Shea and Miao, 2008). In the current study, we proposed a new integration strategy by sandwiching a layer of highly concentrated cell suspension between two layers of cell-seeded PLLA scaffolds, and then suturing the two constructs together, and hypothesized that this cell layer would promote better integration and transition from the cartilage-like to bone-like layers than only suturing two tissues without sandwiched cells. The integration of cartilage and bone layers was assessed by histology and immunohistochemistry and the differentiation of hUCMSCs was examined by gene expression and extracellular matrix (ECM) levels over a 6 week culture period. 


\section{Materials and methods}

\subsection{Isolation of hUCMSCs}

Four cords (three males and one female, $20 \pm 5 \mathrm{~cm}$ in length) were obtained from four patients at the University of Kansas (KU) Medical Center with IRB approvals (KULawrence No. 15402 and KU Medical Center No. 10 951) and were processed within $24 \mathrm{~h}$ following a previous method (Wang et al., 2009a). After cell isolation, hUCMSCs were recorded as passage $1(\mathrm{P} 1)$ and plated at $6000 \mathrm{cells} / \mathrm{cm}^{2}$ in cell culture flasks in a complete culture medium consisting of low-glucose Dulbecco's modified Eagle's medium (DMEMLG; Invitrogen, Carlsbad, CA, USA), 10\% MSC-qualified fetal bovine serum (FBS; Invitrogen) and $1 \%$ penicillin/streptomycin (PS; Invitrogen). P4 hUCMSCs were used for the following experiments.

\subsection{Surface antigens of hUCMSCs}

P4 hUCMSCs were characterized by flow cytometry to analyse specific surface antigens of the mesenchymal cell lineage, including CD29, CD49e, CD73, CD90 and CD105. All supplies were purchased from BD Biosciences (San Jose, CA, USA) except CD73 and CD105 from eBioscience (San Diego, CA, USA). Approximately $0.5 \times 10^{6}$ cells/vial were used for each antigen. Non-specific binding was first blocked with a staining buffer containing 2\% FBS in PBS for 15 min and the cells were then incubated with single-label antigen for $20 \mathrm{~min}$ on ice. Mouse isotype antigens served as a negative control. Flow cytometry analysis was conducted using a FACscan flow cytometer (BD Biosciences).

\subsection{Seeding hUCMSCs into PLLA scaffold}

Non-woven PLLA meshes (50 mg/cc, >95\% porosity; Biomedical Structures LLC, RI, USA) were punched into cylindrical scaffolds ( $5 \mathrm{~mm}$ diameter, $2 \mathrm{~mm}$ thickness). Scaffolds were sterilized using an ethylene oxide chamber following a previous procedure (Wang et al., 2009a). $0.98 \times 10^{6} \mathrm{hUCMSCs}$ in $35 \mu \mathrm{l}$ of the complete medium were seeded in a dropwise manner into each scaffold to achieve a cell density of $25 \times 10^{6}$ cells $/ \mathrm{ml}$ of scaffold. Cell-seeded scaffolds were incubated in a cell culture incubator for $3 \mathrm{~h}$ to allow for cell attachment. To keep the constructs hydrated, $10 \mu \mathrm{l}$ complete medium was added every $1 \mathrm{~h}$. After the $3 \mathrm{~h}$ period, $2 \mathrm{ml}$ of either chondrogenic or osteogenic medium was added into each culture well. Chondrogenic medium consisted of high-glucose DMEM (DMEM-HG; Invitrogen), $1 \%$ non-essential amino acids (NEAA; Invitrogen), $1 \times$ sodium pyruvate (Invitrogen), $1 \times$ insulin transferring selenium premix (ITS premix; BD Biosciences), $50 \mu \mathrm{g} /$ $\mathrm{ml}$ ascorbic acid 2-phosphate (AA2P; Sigma, St Louis, MO, USA), $40 \mu \mathrm{g} / \mathrm{ml}$ L-proline (Sigma), $100 \mathrm{n}_{\mathrm{M}}$ dexamethasone (Sigma) and $10 \mathrm{ng} / \mathrm{ml}$ transforming growth factor beta-1 (TGF $\beta 1 ;$ R\&D Systems, NJ, USA). Osteogenic differentiation medium consisted of the complete culture medium supplemented with $100 \mathrm{n}_{\mathrm{M}}$ dexamethasone, $10 \mathrm{~m}_{\mathrm{M}} \beta$ glycerophosphate ( $\beta$-GP; Sigma), $50 \mu \mathrm{g} / \mathrm{ml}$ AA2P and $10 \mathrm{n}_{\mathrm{M}} 1 \alpha, 25$-dihydroxyvitamin D3 (BIOMOL International, Plymouth Meeting, PA, USA). The media were changed every 2 days for 3 weeks before scaffold integration.

\subsection{Fabrication of osteochondral composites}

After 3 weeks of culture, two PLLA constructs were sutured together using surgical suture needles and a 3-0 silk suture to create osteochondral composites. Four different composite groups were designed: (a) two chondrogenic constructs $(\mathrm{C}-\mathrm{C})$; (2) two osteogenic constructs $(\mathrm{O}-\mathrm{O})$; (3) chondrogenic and osteogenic constructs $(\mathrm{C}-\mathrm{O})$; (4) chondrogenic and osteogenic constructs with a layer of undifferentiated hUCMSCs solution sandwiched between two layers (C-cell-O). In the group of C-cell-O composites, $10 \mu \mathrm{l} 100 \times 10^{6} / \mathrm{ml} \mathrm{hUCMSCs}$ solution was painted onto the surfaces of the osteogenic constructs using a micropipette, and 
chondrogenic and osteogenic constructs were then sutured together with the painted surface toward the chondrogenic constructs. All composites were cultured in a composite culture medium consisting of DMEM-LG, $2 \%$ FBS, $1 \%$ PS, $1 \times$ sodium pyruvate, $1 \times$ ITS, 5 mм $\beta$ GP, $50 \mu \mathrm{g} / \mathrm{ml}$ AA2P, $100 \mathrm{n}_{\mathrm{M}}$ dexamethasone, $40 \mu \mathrm{g} / \mathrm{ml}$ L-proline and $100 \mathrm{ng} / \mathrm{ml}$ insulin-like growth factor-I (IGF-I; PeproTech, Rocky Hill, NJ, USA). IGF-I was chosen for its anabolic capacity in both osteogenesis and chondrogenesis (Kasukawa et al., 2004; Wang and Detamore, 2009). The medium was changed every 2 days for a 3 week period; therefore, the total period of this study was 6 weeks. At week 6 , osteochondral composites, including $\mathrm{C}-\mathrm{C}$, $\mathrm{O}-\mathrm{O}, \mathrm{C}-\mathrm{O}$ and $\mathrm{C}-$ cell- $\mathrm{O}$, were separated into two parts. After separation, both $\mathrm{C}-\mathrm{C}$ and $\mathrm{O}-$ $\mathrm{O}$ composite became two parts and only one of them was randomly selected for analysis.

Both $\mathrm{C}-\mathrm{O}$ and $\mathrm{C}-$ cell-O composites became two different parts, osteogenic and chondrogenic, and both of them were used for the assays.

\subsection{Biochemical assays}

Biochemical assays $(n=4)$ included the quantification of DNA, glycosaminoglycans (GAGs), hydroxyproline (HYP) and calcium deposition at weeks 0,3 and 6. To measure DNA, GAG and HYP contents, the samples were digested in $1.5 \mathrm{ml} 120 \mu \mathrm{g} / \mathrm{ml}$ papain solution at $60{ }^{\circ} \mathrm{C}$ overnight. DNA and GAG contents were determined using a PicoGreen kit (Invitrogen) and a dimethylmethylene blue (DMMB) dye binding assay (Biocolor, Belfast, UK), following the manufacturers' respective procedures. HYP contents were determined using a HYP assay protocol described in the literature (Wang et al., 2009a). To measure calcium contents, samples were digested in $1 \mathrm{~N}$ acetic acid overnight at room temperature. Calcium content was measured using an ortho-cresolphthalein complexone (OCPC) method (ter Brugge and Jansen, 2002). $10 \mu \mathrm{l}$ digestion solution and $300 \mu \mathrm{l}$ assay reagent were mixed and incubated for $10 \mathrm{~min}$ at room temperature and then read at $575 \mathrm{~nm}$.

\subsection{Immunohistochemistry and histology}

Constructs were frozen in an optimal cutting temperature (OCT) medium (Sakura Finetek; Torrance, CA, USA) and sectioned at a thickness of $10 \mu \mathrm{m}$ using a cryostat (Microm; Thermo Scientific, Waltham, MA, USA). Types I and II collagen and aggrecan were examined immunohistochemically, using a BioGenex i6000 autostainer (BioGenex, San Ramon, CA, USA) as described previously (Detamore and Athanasiou, 2005; Detamore et al., 2005). Primary antibodies included the mouse monoclonal IgG anti-collagen I ( $1: 1500$ dilution; Accurate Chemical and Scientific, Westbury, NY, USA), mouse monoclonal IgG anti-collagen II ( $1: 1000$ dilution; Chondrex, Redmond, WA, USA) and mouse monoclonal IgG anti-aggrecan ( $1: 50$ dilution; Abcam, Cambridge, MA, USA). In brief, endogenous peroxidase activity was inhibited using $1 \%$ hydrogen peroxide, blocked in horse serum and incubated with primary antibodies. Following the incubation, the sections were then incubated with a streptavidin-linked horse anti-mouse $\operatorname{IgG}$ secondary antibody (Vector Laboratories, Burlingame, CA, USA). After the incubation with secondary antibodies, the sections were incubated with an avidin-biotinylated enzyme complex (ABC Complex; Vector Laboratories) and were finally stained with VIP substrate (purple colour; Vector Laboratories) and counterstained with Harris haematoxylin (blue colour; Fisher Scientific, PA, USA). Histological analyses were performed to visualize the distribution of GAGs and cells using safranin $\mathrm{O} /$ fast green staining and to detect calcium minerals using alizarin red staining.

\subsection{Real-time reverse transcription polymerase chain reaction (RT-PCR)}

Total RNA was extracted with TRIzol reagents (Invitrogen) and mRNA was reversetranscribed to cDNA using a High-Capacity cDNA Archive Kit (Applied Biosystems, Foster City, CA, USA). Quantitative PCR reactions were performed in an Applied Biosystems 7500 Fast System. TaqMan gene expression assay kits (Applied Biosystems) were used to 
measure the transcript levels of genes, including collagen I (Hs00164004_m1), collagen II (Hs00156568_m1), aggrecan (Hs00153936_m1), osterix (OSX; Hs00541729_m1), runtrelated transcription factor $2(R U N X 2$; Hs00231692_m1), osteocalcin $(O C N$; Hs01587813_g1), bone sialoprotein (BSP, Hs00173720_m1), and glyceraldehyde 3phosphate dehydrogenase (GAPDH; Hs99999905_m1). All genes were tested with the constructs at weeks 0 and 3 and with the $\mathrm{C}-\mathrm{C}$ and $\mathrm{O}-\mathrm{O}$ composites at week 6 . The chondrogenic parts of the $\mathrm{C}-\mathrm{O}$ and $\mathrm{C}-$-cell-O composites were used to detect types I and II collagen, and aggrecan genes and their osteogenic parts were used to detect the osteogenic genes, including RUNX2, OSX, OCN and BSP. The relative expression level for each target gene was evaluated using the $2^{-\Delta C t}$ method (Livak and Schmittgen, 2001).

\subsection{Data analysis}

All data were expressed as means \pm standard deviation (SD) and analysed by analysis of variance (ANOVA) followed by Tukey's honestly significant difference (HSD) post hoc tests. A statistical threshold of $p<0.05$ was used to detect whether there were statistical significances among different groups.

\section{Results}

\subsection{Surface antigens of hUCMSCs}

Passage 4 hUCMSCs were characterized by surface antigen expression using flow cytometry (Figure 1). hUCMSCs expressed high levels of matrix markers, including CD44 (97.3\%) and CD105 (97.5\%), integrin markers CD29 (98.0\%) and MSC markers, including CD49e (96.5\%), CD73 (95.2\%) and CD90 (98.8\%), while hUCMSCs were negative to haematopoietic markers including CD34 $(<1 \%)$ and CD45 $(<1 \%)$.

\subsection{DNA contents}

In general, DNA contents in the chondrogenic groups decreased over the 6 week period ( $p<$ 0.05 ) (Figure 2a). Specifically, the DNA content decreased by $40 \%$ in the chondrogenic constructs from weeks 0 to $3(p<0.05)$ and was maintained from weeks 3 and $6(p>0.05)$. At week 6, the chondrogenic part of the $\mathrm{C}-$ cell-O composite had a similar DNA content to the DNA content at week 3, while it had 1.3 and 1.4 times higher DNA contents than the C$\mathrm{C}$ composites $(p>0.05)$ and the chondrogenic parts of $\mathrm{C}-\mathrm{O}$ composites $(p<0.05)$ at week 6 , respectively. The DNA content was maintained in osteogenic constructs during the first 3 week period and decreased by $23 \%$ from weeks 3 to 6 in the $\mathrm{O}-\mathrm{O}$ composites and the osteogenic parts of $\mathrm{C}-\mathrm{O}$ composites $(p<0.05)$. The osteogenic parts of the $\mathrm{C}-$ cell-O composites had a comparable DNA content to the osteogenic constructs at week $3(p>0.05)$ and had 1.3 times higher DNA contents than the $\mathrm{O}-\mathrm{O}$ composites and the osteogenic parts of $\mathrm{C}-\mathrm{O}$ composites $(p<0.05)$ at week 6 . With regard to the comparison between chondrogenic and osteogenic groups, all osteogenic groups had a higher DNA content than chondrogenic groups at both weeks 3 and $6(p<0.05)$. There was 1.6 times more DNA in the osteogenic constructs than in the chondrogenic constructs at week $3(p<0.05)$. At week 6 , the DNA content in the $\mathrm{O}-\mathrm{O}$ composites was 1.5 times higher than in the $\mathrm{C}-\mathrm{C}$ composites $(p<0.05)$. The osteogenic parts of both $\mathrm{C}-\mathrm{O}$ and $\mathrm{C}-$ cell-O composites had 1.6 times more DNA than their chondrogenic parts $(p<0.05)$.

\subsection{GAG content}

GAG contents increased markedly in the chondrogenic groups in the first 3 weeks, with 2.7 times higher values at week 3 than at week $0(p<0.05)$ and were maintained from weeks 3 to $6(p>0.05)$ (Figure 2b). There was no significant difference in GAG contents among all chondrogenic groups at week 6 . All osteogenic groups had similar GAG contents to each 
other over 6 weeks, although there was a slight drop from weeks 3 to 6 in all composites ( $p$ $>0.05)$. In comparison to the osteogenic groups, the GAG contents in the chondrogenic groups were significantly higher at both weeks 3 and $6(p<0.05)$. The chondrogenic constructs had 2.3 times more GAGs than the osteogenic constructs at week $3(p<0.05)$. At week 6 , the $\mathrm{C}-\mathrm{C}$ composites had 2.4 times more GAGs than the $\mathrm{O}-\mathrm{O}$ composites $(p<0.05)$. The GAG contents in the chondrogenic parts of both the $\mathrm{C}-\mathrm{O}$ and $\mathrm{C}-$ cell-O $\mathrm{O}$ composites were 2.7 times higher than their osteogenic parts $(p<0.05)$.

\subsection{Hydroxyproline (HYP) contents}

In the chondrogenic groups, HYP contents increased continuously from week 0 to 6 ( $p<$ 0.05 ) (Figure 2c). The highest HYP production was observed in the $\mathrm{C}-\mathrm{C}$ composites at week 6 with 156 and 2.6 times more HYP than the chondrogenic constructs at weeks 0 and 3 , respectively $(p<0.05)$. At week 6 , the $\mathrm{C}-\mathrm{C}$ composites also had 1.6 and 1.3 times more HYP than the chondrogenic parts of the $\mathrm{C}-\mathrm{O}$ and $\mathrm{C}-$ cell-O groups $(p<0.05)$, respectively, while there was no significant difference between the $\mathrm{C}-\mathrm{O}$ and $\mathrm{C}-$ cell-O composites. Like the chondrogenic groups, the osteogenic groups also had an increased HYP content throughout the 6 week culture period $(p<0.05)$, whereas no significant differences were discerned among all groups at week 6 . With regard to the comparison between the chondrogenic and osteogenic groups, the chondrogenic groups had significantly higher HYP contents than the osteogenic groups over 6 weeks $(p<0.05)$. At week 3 , the chondrogenic constructs had 4.6 times more HYP than the osteogenic constructs. At week 6 , the $\mathrm{C}-\mathrm{C}$ composites had 4.9 times more HYP than the $\mathrm{O}-\mathrm{O}$ composites $(p<0.05)$. HYP contents in the chondrogenic parts of the $\mathrm{C}-\mathrm{O}$ and $\mathrm{C}-$ cell-O composites were 3.1 and 3.5 times higher than in their osteogenic parts, respectively $(p<0.05)$.

\subsection{Calcium contents}

Calcium contents in the chondrogenic groups slightly increased from weeks 0 to 6 , but without significant differences (Figure 2d). In contrast, calcium contents drastically increased over time in the osteogenic groups $(p<0.05)$. At week 6 , the $\mathrm{O}-\mathrm{O}$ composites had the highest calcium contents among all composites, with 1.5 and 2.1 times more calcium than the osteogenic parts of the $\mathrm{C}-\mathrm{O}$ and $\mathrm{C}-$ cell-O groups, respectively $(p<0.05)$. Compared to calcium contents in the chondrogenic groups, which were $<1 \mu \mathrm{g} / \mu \mathrm{g}$ DNA, all osteogenic groups had higher calcium deposition, in the range 2.4-9.4 $\mu \mathrm{g} / \mu \mathrm{g}$ DNA over the 6 week period $(p<0.05)$.

\subsection{Histology and immunohistochemistry}

Chondrogenic and osteogenic potentials of hUCMSCs and scaffold integration at the interface between the chondrogenic and osteogenic parts of all composites were evaluated by histology and immunohistochemistry. At week 3 (Figure 3), the chondrogenic constructs had weak staining for type I collagen and aggrecan by immunohistochemistry, and moderate staining of GAGs by safranin-O staining, while no positive staining was observed in type II collagen immunohistochemical staining and alizarin red staining for calcium deposition. In contrast, in the osteogenic constructs, calcium deposition and type II collagen were observed in the peripheral region of the constructs, while there was no positive staining for type I collagen, aggrecan and GAGs.

At week 6 (Figure 4), all stainings presented a more homogeneous cell and matrix distribution in the chondrogenic groups than in the osteogenic groups. Cells and ECM were mainly located at the peripheral area in the osteogenic groups. Regarding the scaffold integration at week 6 , all stainings revealed that the $\mathrm{C}-$ cell-O composite exhibited the best integration and transition of ECM between two layers among all composites. The $\mathrm{C}-\mathrm{O}$ composites also had a good integration in the middle of the interface, while the edge of the 
interface was absent of cells and ECMs and formed large V-shaped dents. Another noticeable difference between the $\mathrm{C}-$ cell-O $\mathrm{O}$ and $\mathrm{C}-\mathrm{O}$ composites was the distribution and amount of calcium deposition, type II collagen and aggrecan. In the $\mathrm{C}-$ cell-O composites at week 6, calcium was distributed only on the surface exposed to the cell culture medium and there were no calcium on the surface facing the osteochondral interface, although calcium was deposited around the surface of osteogenic constructs at week 3 . In the $\mathrm{C}-\mathrm{O}$ composites, calcium was distributed on all surfaces of the osteogenic parts and led to a sharp transition of calcium from chondrogenic to osteogenic parts at week 6 . Moreover, the $\mathrm{C}-\mathrm{O}$ composites had stronger staining of calcium in the osteogenic parts, and stronger type II collagen and aggrecan staining in the chondrogenic parts, than in the C-cell-O composites. With regard to the $\mathrm{C}-\mathrm{C}$ and $\mathrm{O}-\mathrm{O}$ composites, there was a strong positive staining of type I collagen, a weak staining of aggrecan and a trace staining of type II collagen in the $\mathrm{C}-\mathrm{C}$ composites by immunohistochemistry, and histology revealed no GAG staining and no calcium deposition. In contrast, the $\mathrm{O}-\mathrm{O}$ composites had a stronger calcium staining and a more intense type I collagen staining on the borders. The $\mathrm{C}-\mathrm{C}$ composites also had dents similar to the $\mathrm{C}-\mathrm{O}$ composites at the edge with homogeneous ECM distribution at week 6, while the $\mathrm{O}-\mathrm{O}$ composites presented an obvious discontinuity of all types of stainings between the two parts.

\subsection{Gene expression}

At weeks 3 and 6, chondrogenic genes, including type II collagen and aggrecan, increased significantly in the chondrogenic groups $(p<0.05)$, while these genes did not appear in the osteogenic groups at week 3 and the $\mathrm{O}-\mathrm{O}$ composites at week 6 (Figure 5a). The expression of type I collagen genes was upregulated in all tested groups $(p<0.05)$ (Figure 5a). The $R U N X 2$ gene in osteogenic constructs increased by 20 -fold during weeks $0-3(p<0.05)$ and remained at a high level during weeks 3-6, while other osteogenic genes, including $O S X$, $O C N$ and $B S P$, did not have significant increases during the 6 -week culture $(p>0.05)$. None of the osteogenic genes in the chondrogenic constructs at week 3 and the $\mathrm{C}-\mathrm{C}$ composites at week 6 significantly increased over 6 weeks.

\section{Discussion and conclusion}

The aim of this study was to investigate the feasibility of fabricating an integrated osteochondral construct using hUCMSCs and an integration strategy of sandwiching cells between two layers. As a fetus-derived stem cell source, hUCMSCs have various benefits over adult stem cell sources, such as faster proliferation, non-invasive collection and ample availability. Here, we applied hUCMSCs to osteochondral tissue engineering in a composite approach. Chondrogenic and osteogenic differentiation was observed in the first 3 weeks, as evidenced by the expression of type II collagen and RUNX2 genes, respectively, and continued with the increase of extracellular matrix during the last 3 weeks. To promote the integration and transition on the osteochondral interface, we introduced the approach of sandwiching a layer of undifferentiated hUCMSCs between chondrogenic and osteogenic constructs and hypothesized that this cell layer would help to develop a more well-integrated transition between them. Indeed, we observed the best integration in the $\mathrm{C}-$ cell-O group among all groups by immunohistochemistry and histology.

All chondrogenic groups not only appeared cartilaginous by immunohistochemical and histological observation but were quantitatively characterized by rich ECM, including GAG and HYP production. Immunohistochemical analysis showed a small amount of type II collagen and aggrecan and an abundant amount of type I collagen in the chondrogenic groups. Histological analysis showed rich staining for GAGs in the chondrogenic groups at week 3, although these GAGs did not aggregate to form a large amount of aggrecan, as indicated by only a weak aggrecan staining. RT-PCR analysis also revealed the upregulation 
of cartilage-specific genes, including type II collagen and aggrecan. These data collectively indicated that hUCMSCs progressed toward a chondrogenic lineage in 3D PLLA scaffolds. However, it must be noted that the matrix was more fibrous in nature due to the existence of a large amount of type I collagen. Exposed to osteogenic signals, hUCMSCs differentiated toward an osteogenic lineage, as evidenced by calcium deposition and the upregulation of $R U N X 2$ gene expression in the first 3 weeks. During this period, the distribution of type II collagen around the periphery of the osteogenic groups, which diminished with time, may have indicated a transient heterogeneity of UCMSCs at week 3 . The RUNX2 gene expression was maintained in the osteogenic groups during the subsequent culture, while calcium contents continued to increase over time. Despite this evidence for early-stage osteogenic differentiation, the low levels of the other osteogenic genes, including $B S P, O S X$ and $O C N$, may indicate that the mature osteoblast stage was not reached within 6 weeks, necessitating future optimization of differentiation conditions and/or a longer differentiation period.

In composite culture medium from weeks 3 to 6 , the cells in the $\mathrm{C}-\mathrm{C}$ composites and the chondrogenic parts of the $\mathrm{C}-\mathrm{O}$ and $\mathrm{C}-$ cell- $\mathrm{O}$ composites did not appear to be undergoing osteogenic differentiation, although the composite media included supplements such as dexamethasone and $\beta$-glycerophosphate, which suggests the possibility that the hUCMSCs may have lost their 'stemness' and differentiated toward chondrocyte-like cells in the first 3 weeks chondrogenic exposure. However, we did observe the disappearance of GAGs at week 6 , revealed by negative safranin $O$ staining, probably due to the absence of chondrogenic signals in the composite media. Furthermore, the cells in the $\mathrm{O}-\mathrm{O}$ composites and the osteogenic parts of the $\mathrm{C}-\mathrm{O}$ and $\mathrm{C}-$ cell-O composites did not undergo chondrogenic differentiation, to which some of the following reasons may contribute. First, hUCMSCs may differentiate toward osteoblast-like cells during the first 3 weeks. Second, at week 6, the composite media included the osteogenic supplements, dexamethasone and $\beta$. glycerophosphate, while excluding chondrogenic signals, TGF $\beta$ I. Based on DNA content, the cell number appeared to decrease with culture time in both osteogenic and chondrogenic groups. This drop in cell number is a common theme we have observed with non-woven PLLA (Wang et al., 2009b) and also with PGA scaffolds (Wang et al., 2009c). One possible reason for the loss of cells could be that the cells were seeded at a high seeding density, which may limit cell proliferation; also, dexamethasone, an inhibitor of cell proliferation, existed in all types of media used in this study. Moreover, it appears that cell adhesion suffers on these types of scaffolds without some type of adhesion moiety. At week 6, we observed more cells in the $\mathrm{C}-$ cell-O composites than in other composites, a lower HYP content per DNA in the $\mathrm{C}-$ cell-O composites than in the $\mathrm{C}-\mathrm{C}$ composites, and a lower calcium content per DNA in the $\mathrm{C}-$ cell- $\mathrm{O}$ composites than in the $\mathrm{O}-\mathrm{O}$ composites. There are two factors contributing to these differences. First, a higher cell number in C-cell-O composites was partly due to the addition of sandwiched cells, while similar HYP and calcium contents per construct were detected between the $\mathrm{C}-$ cell- $\mathrm{O}$ composites and the $\mathrm{C}-\mathrm{C}$ and $\mathrm{O}-\mathrm{O}$ composites, thus resulting in a lower HYP and calcium per DNA than in the $\mathrm{C}-\mathrm{C}$ and $\mathrm{O}-\mathrm{O}$ composites. Second, endogenous chemical signals released by cells in chondrogenic, osteogenic or sandwiched layers into the media may have affected cell proliferation and ECM synthesis in the opposite layer.

In osteochondral tissue engineering, a major challenge is to integrate chondrogenic and osteogenic regions seamlessly. For this purpose, various methods have been adopted in previous studies (Wakitani et al., 1994; Angele et al., 1999; Schaefer et al., 2000, 2002; Gao et al., 2001; Weng et al., 2001; Cao et al., 2003; Alhadlaq and Mao, 2003, 2005; Alhadlaq et al., 2004; Tuli et al., 2004; Malafaya and Reis, 2009; Guo et al., 2009, 2010; Mrosek et al., 2010). In our study, better integration was achieved at the interface between chondrogenic and osteogenic parts when we included a layer of undifferentiated cells in between. After 6 
weeks of culture, there appeared to be a higher cell number with intensive ECM staining at the interface of $\mathrm{C}-$ cell-O composites, indicated by positive immunohistochemical and histological staining. These ECMs on the interface served as a filler to fill the gaps caused by the simple suturing techniques in the other groups and may have acted as a biological glue to bridge the chondrogenic and osteogenic parts, thus resulting in better integration between constructs. Compared to the existence and sharp transition of calcium on the interface in the $\mathrm{C}-\mathrm{O}$ composite, calcium deposition gradually disappeared across the interface in the $\mathrm{C}-$ cell-O composite at week 6 , leading to a better transition between scaffolds and also indicating that the sandwiched cells may affect the calcium remodelling directly or indirectly. The sandwiched cells seem to affect chondrogenic differentiation in the chondrogenic parts of the $\mathrm{C}-$ cell-O composites, as we observed weaker staining of type II collagen and aggrecan. To further track sandwiched cells and associated gene expression, fluorescent tracking techniques for cells can be used to investigate cell viability and migration, and gene expression of these cells can also be achieved by in situ hybridization.

Immunohistochemical and histological staining also revealed a more homogeneous distribution of cells and ECM inside chondrogenic constructs than in osteogenic constructs at weeks 3 and 6 . The different nature of chondrocyte-like and osteoblast-like cells may have contributed to this difference. Compared to chondrocytes, osteoblasts reside in an environment abundant in oxygen and nutrients, due to the existence of blood vessels, indicating that osteoblasts may have higher demands for oxygen and nutrients and thus may migrate toward the peripheral area of constructs. Moreover, it is surprising that we observed a clear discontinuity in the $\mathrm{O}-\mathrm{O}$ composite and a better fusion in the $\mathrm{C}-\mathrm{C}$ composites, because one of the motivations of using osteochondral composites is to take advantage of a better ability to fuse a bone-to-bone interface than a cartilage-to-cartilage interface. The absence of blood vessels in vitro may contribute to this discrepancy.

In conclusion, a novel osteochondral construct was fabricated using hUCMSCs as an alternative to mature cells and other stem cells. hUCMSCs allowed the fabrication of osteochondral constructs from a single cell source with the chondrogenic and osteogenic potentials, as demonstrated here. A new integration strategy was developed by sandwiching undifferentiated hUCMSCs between the chondrogenic and osteogenic parts before suturing them. The connection of chondrogenic and osteogenic constructs was significantly improved by the sandwiched cells and their ECM on the interface. Future experiments will be directed toward both mechanical and biochemical evaluation of these constructs in vitro and in vitro after a long-term culture and/or implantation for more than 6 weeks.

\section{Acknowledgments}

We gratefully acknowledge Dr Stephen H. Benedict and Kelli M. Cool at the University of Kansas for their kind assistance with flow cytometry analysis. This study was supported by NIH R21 Grant No. DE017673-01, the Arthritis Foundation and the State of Kansas.

\section{References}

Alhadlaq A, Elisseeff JH, Hong L, et al. Adult stem cell-driven genesis of humanshaped articular condyle. Ann Biomed Eng. 2004; 32:911-923. [PubMed: 15298429]

Alhadlaq A, Mao JJ. Tissue-engineered neogenesis of human-shaped mandibular condyle from rat mesenchymal stem cells. J Dent Res. 2003; 82:951-956. [PubMed: 14630893]

Alhadlaq A, Mao JJ. Tissue-engineered osteochondral constructs in the shape of an articular condyle. J Bone Joint Surg Am. 2005; 87:936-944. [PubMed: 15866954]

Angele P, Kujat R, Nerlich M, et al. Engineering of osteochondral tissue with bone marrow mesenchymal progenitor cells in a derivatized hyaluronan-gelatin composite sponge. Tissue Eng. 1999; 5:545-554. [PubMed: 10611546] 
Bailey MM, Wang L, Bode CJ, et al. A comparison of human umbilical cord matrix stem cells and temporomandibular joint condylar chondrocytes for tissue engineering temporomandibular joint condylar cartilage. Tissue Eng. 2007; 13:2003-2010. [PubMed: 17518722]

Cao T, Ho KH, Teoh SH. Scaffold design and in vitro study of osteochondral coculture in a threedimensional porous polycaprolactone scaffold fabricated by fused deposition modeling. Tissue Eng. 2003; 9(suppl 1):S103-112. [PubMed: 14511474]

Detamore MS, Athanasiou KA. Use of a rotating bioreactor toward tissue engineering the temporomandibular joint disc. Tissue Eng. 2005; 11:1188-1197. [PubMed: 16144455]

Detamore MS, Orfanos JG, Almarza AJ, et al. Quantitative analysis and comparative regional investigation of the extracellular matrix of the porcine temporomandibular joint disc. Matrix Biol. 2005; 24:45-57. [PubMed: 15749001]

Fu YS, Cheng YC, Lin MY, et al. Conversion of human umbilical cord mesenchymal stem cells in Wharton's jelly to dopaminergic neurons in vitro: potential therapeutic application for Parkinsonism. Stem Cells. 2006; 24:115-124. [PubMed: 16099997]

Gao J, Dennis JE, Solchaga LA, et al. Tissue-engineered fabrication of an osteochondral composite graft using rat bone marrow-derived mesenchymal stem cells. Tissue Eng. 2001; 7:363-371. [PubMed: 11506726]

Grayson WL, Chao PH, Marolt D, et al. Engineering custom-designed osteochondral tissue grafts. Trends Biotechnol. 2008; 26:181-189. [PubMed: 18299159]

Guo X, Park H, Liu G, et al. In vitro generation of an osteochondral construct using injectable hydrogel composites encapsulating rabbit marrow mesenchymal stem cells. Biomaterials. 2009; 30:2741-2752. [PubMed: 19232711]

Guo X, Park H, Young S, et al. Repair of osteochondral defects with biodegradable hydrogel composites encapsulating marrow mesenchymal stem cells in a rabbit model. Acta Biomater. 2010; 6:39-47. [PubMed: 19660580]

Ishaug-Riley SL, Okun LE, Prado G, et al. Human articular chondrocyte adhesion and proliferation on synthetic biodegradable polymer films. Biomaterials. 1999; 20:2245-2256. [PubMed: 10614931]

Karahuseyinoglu S, Cinar O, Kilic E, et al. Biology of stem cells in human umbilical cord stroma: in situ and in vitro surveys. Stem Cells. 2007; 25:319-331. [PubMed: 17053211]

Kasukawa Y, Miyakoshi N, Mohan S. The anabolic effects of GH/IGF system on bone. Curr Pharm Des. 2004; 10:2577-2592. [PubMed: 15320746]

Livak KJ, Schmittgen TD. Analysis of relative gene expression data using real-time quantitative PCR and the $2\left(-\Delta_{C_{t}}\right)$ method. Methods. 2001; 25:402-408. [PubMed: 11846609]

Malafaya PB, Reis RL. Bilayered chitosan-based scaffolds for osteochondral tissue engineering: influence of hydroxyapatite on in vitro cytotoxicity and dynamic bioactivity studies in a specific doublechamber bioreactor. Acta Biomater. 2009; 5:644-660. [PubMed: 18951857]

Mrosek EH, Schagemann JC, Chung HW, et al. Porous tantalum and poly- $\epsilon$-caprolactone biocomposites for osteochondral defect repair: preliminary studies in rabbits. J Orthop Res. 2010; 28:141-148. [PubMed: 19743507]

O'Shea TM, Miao X. Bilayered scaffolds for osteochondral tissue engineering. Tissue Eng B Rev. 2008; 14:447-464.

Richardson SM, Curran JM, Chen R, et al. The differentiation of bone marrow mesenchymal stem cells into chondrocyte-like cells on poly-1-lactic acid (PLLA) scaffolds. Biomaterials. 2006; 27:4069-4078. [PubMed: 16569429]

Sarugaser R, Lickorish D, Baksh D, et al. Human umbilical cord perivascular (HUCPV) cells: a source of mesenchymal progenitors. Stem Cells. 2005; 23:220-229. [PubMed: 15671145]

Schaefer D, Martin I, Jundt G, et al. Tissue-engineered composites for the repair of large osteochondral defects. Arthritis Rheum. 2002; 46:2524-2534. [PubMed: 12355501]

Schaefer D, Martin I, Shastri P, et al. In vitro generation of osteochondral composites. Biomaterials. 2000; 21:2599-2606. [PubMed: 11071609]

Stevens MM, Qanadilo HF, Langer R, et al. A rapid-curing alginate gel system: utility in periosteumderived cartilage tissue engineering. Biomaterials. 2004; 25:887-894. [PubMed: 14609677]

ter Brugge PJ, Jansen JA. In vitro osteogenic differentiation of rat bone marrow cells subcultured with and without dexamethasone. Tissue Eng. 2002; 8:321-331. [PubMed: 12031120] 
Tuli R, Nandi S, Li WJ, et al. Human mesenchymal progenitor cell-based tissue engineering of a single-unit osteochondral construct. Tissue Eng. 2004; 10:1169-1179. [PubMed: 15363173]

Wakitani S, Goto T, Pineda SJ, et al. Mesenchymal cell-based repair of large, full-thickness defects of articular cartilage. J Bone Joint Surg Am. 1994; 76:579-592. [PubMed: 8150826]

Wang HS, Hung SC, Peng ST, et al. Mesenchymal stem cells in the Wharton's jelly of the human umbilical cord. Stem Cells. 2004; 22:1330-1337. [PubMed: 15579650]

Wang L, Detamore MS. Insulin-like growth factor-I improves chondrogenesis of predifferentiated human umbilical cord mesenchymal stromal cells. J Orthop Res. 2009; 27:1109-1115. [PubMed: 19195026]

Wang L, Seshareddy K, Weiss ML, et al. Effect of initial seeding density on human umbilical cord mesenchymal stromal cells for fibrocartilage tissue engineering. Tissue Eng A. 2009a; 15:1009_ 1017.

Wang L, Singh M, Bonewald LF, et al. Signalling strategies for osteogenic differentiation of human umbilical cord mesenchymal stromal cells for 3D bone tissue engineering. J Tissue Eng Regen Med. 2009b; 3:398-404. [PubMed: 19434662]

Wang L, Tran I, Seshareddy K, et al. A comparison of human bone marrow-derived mesenchymal stem cells and human umbilical cord-derived mesenchymal stromal cells for cartilage tissue engineering. Tissue Eng A. 2009c; 15:2259-2266.

Weiss ML, Troyer DL. Stem cells in the umbilical cord. Stem Cell Rev. 2006; 2:155-162. [PubMed: 17237554]

Weng Y, Cao Y, Silva CA, et al. Tissue-engineered composites of bone and cartilage for mandible condylar reconstruction. J Oral Maxillofac Surg. 2001; 59:185-190. [PubMed: 11213987]

Zwingmann J, Mehlhorn AT, Sudkamp N, et al. Chondrogenic differentiation of human articular chondrocytes differs in biodegradable PGA/PLA scaffolds. Tissue Eng. 2007; 13:2335-2343. [PubMed: 17691868] 


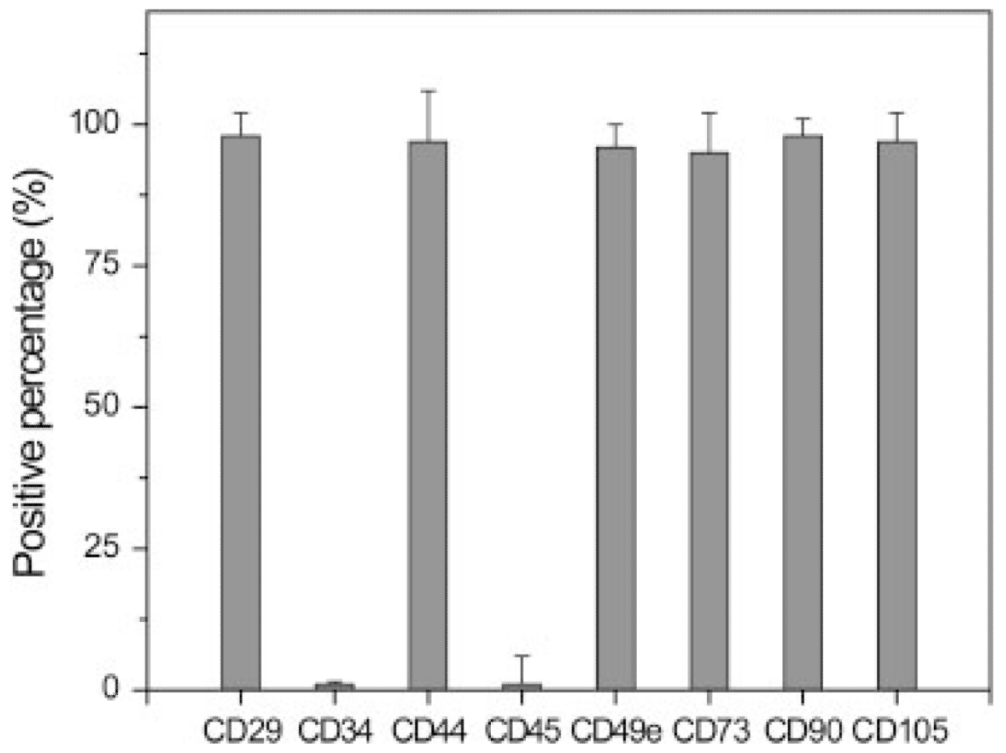

Figure 1.

Flow cytometry analysis of surface antigens on human umbilical cord mesenchymal cells (hUCMSCs) $(n=4)$. hUCMSCs expressed a set of MSC markers and did not express haematopoietic markers 

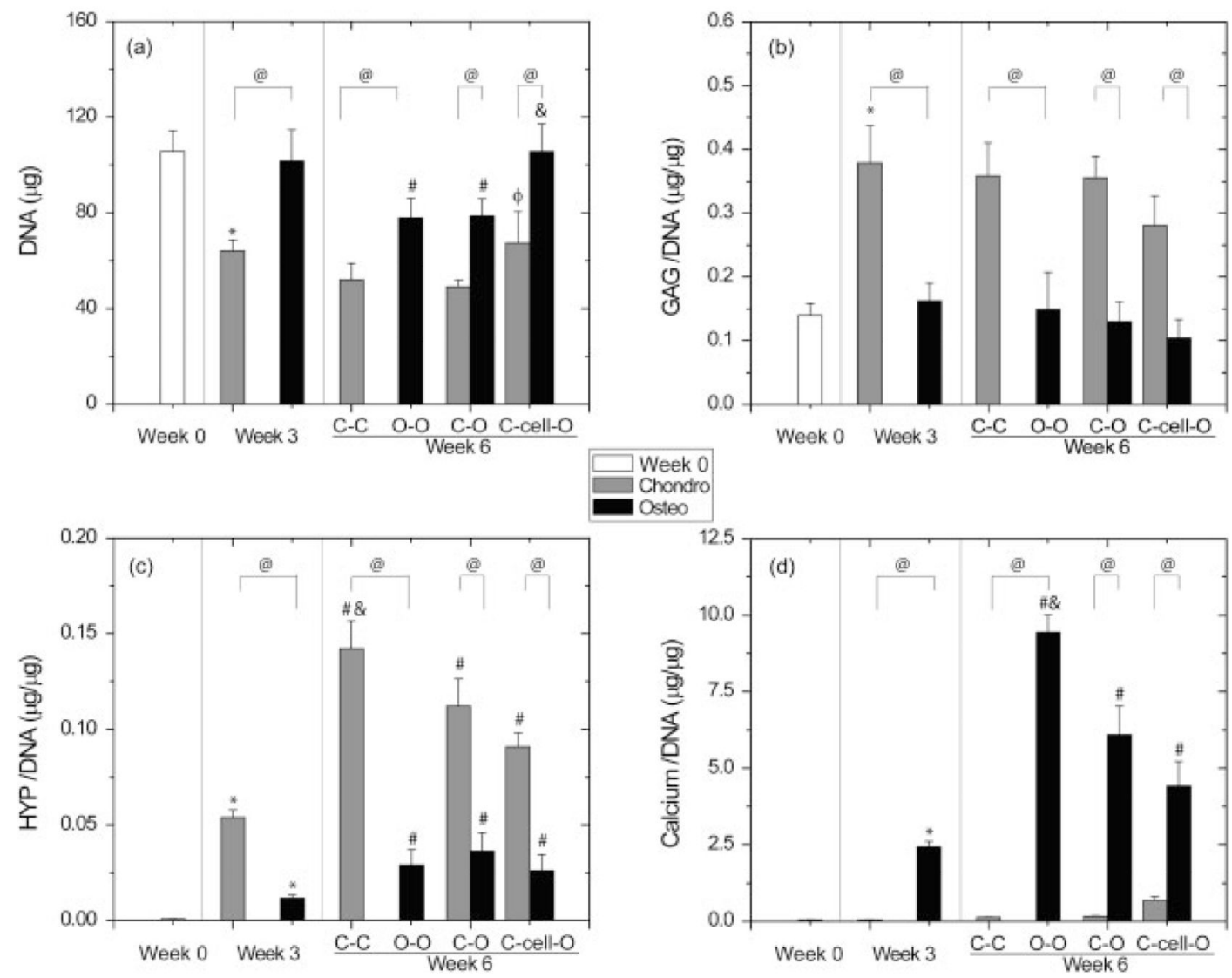

Figure 2.

Biochemical analyses (mean $\pm \mathrm{SD}, n=4$ ) for the individual chondrogenic and osteogenic constructs at week 3 and for the chondrogenic and osteogenic parts of the composites at week 6. At week 6, osteochondral composites, including $\mathrm{C}-\mathrm{C}, \mathrm{O}-\mathrm{O}, \mathrm{C}-\mathrm{O}$ and $\mathrm{C}-\mathrm{cell}-\mathrm{O}$, were separated into two parts. In the $\mathrm{C}-\mathrm{C}$ and $\mathrm{O}-\mathrm{O}$ composites, only one part was used for the assays. In the $\mathrm{C}-\mathrm{O}$ and $\mathrm{C}-$ cell-O composites, both parts, osteogenic and chondrogenic, were used separately for the assays: (a) DNA content; (b) normalized glycosaminoglycan (GAG) content; (c) normalized hydroxyproline (HYP) content; and (d) normalized calcium content. The chondrogenic constructs had lower DNA and calcium contents and higher GAG and HYP contents than the osteogenic constructs at both weeks 3 and 6 . The C-cell-O composites had higher DNA contents than other composites at week 6. *, Statistically significant difference between weeks 0 and 3; \#, statistically significant difference between weeks 3 and 6 among either chondrogenic or osteogenic groups; $\varphi$, statistically significant difference between the $\mathrm{C}-\mathrm{O}$-cell composites and the $\mathrm{C}-\mathrm{O}$ composites at week 6 ; \&, statistically significant difference from the other two groups in either chondrogenic or osteogenic parts at week 6; @, statistically significant difference between chondrogenic and osteogenic groups. Chondro, chondrogenic groups; osteo, osteogenic groups; $\mathrm{C}-\mathrm{C}$, composite containing two chondrogenic constructs; $\mathrm{O}-\mathrm{O}$, composite containing two osteogenic constructs; $\mathrm{C}-\mathrm{O}$, composite containing chondrogenic and osteogenic constructs; $\mathrm{C}-$ cell-O, composite containing chondrogenic and osteogenic constructs with a layer of undifferentiated hUCMSCs at the interface 

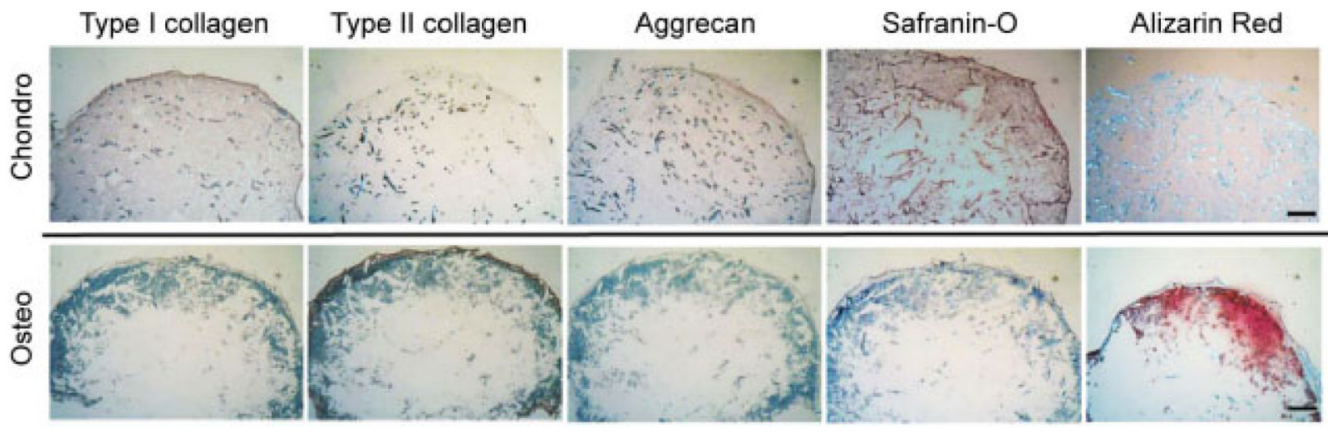

Figure 3.

Immunohistochemical staining for types I and II collagen and aggrecan and histological stainings including safranin-O staining for glycosaminoglycan (GAG) and alizarin red staining for calcium at week $3(n=2)$. Moderate aggrecan and GAG stainings indicated differentiation toward a chondrogenic lineage in chondrogenic constructs. A strong calcium staining indicated differentiation toward an osteogenic lineage in osteogenic constructs. Scale bar $=250 \mu \mathrm{m}$ 


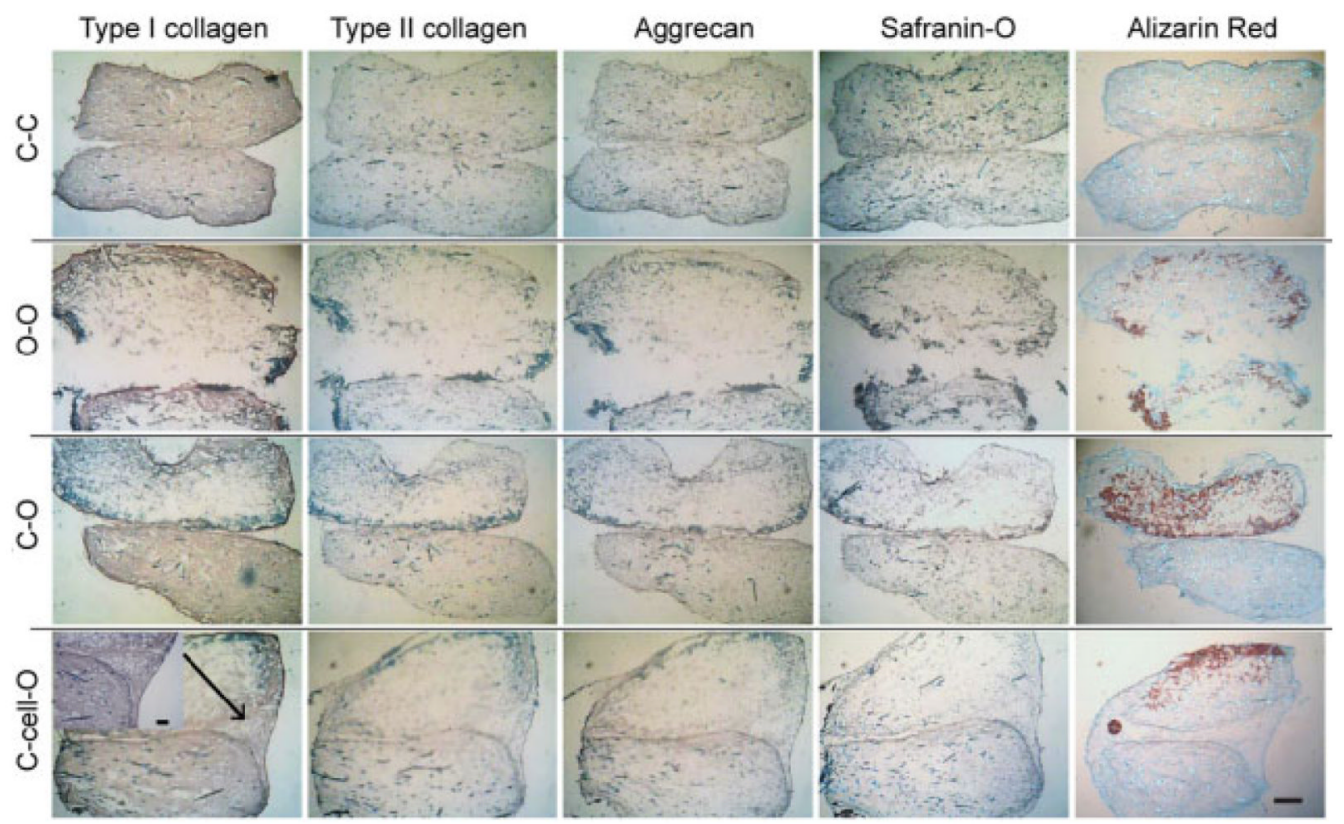

Figure 4.

Immunohistochemical staining for types I and II collagen and aggrecan, and histological stainings including safranin-O staining for glycosaminoglycans (GAGs) and alizarin red staining for calcium at week $6(n=2)$. All stainings revealed better integration and transition in $\mathrm{C}-$ cell-O groups than in the $\mathrm{C}-\mathrm{O}$ groups. Scale bar $=500 \mu \mathrm{m}$ 

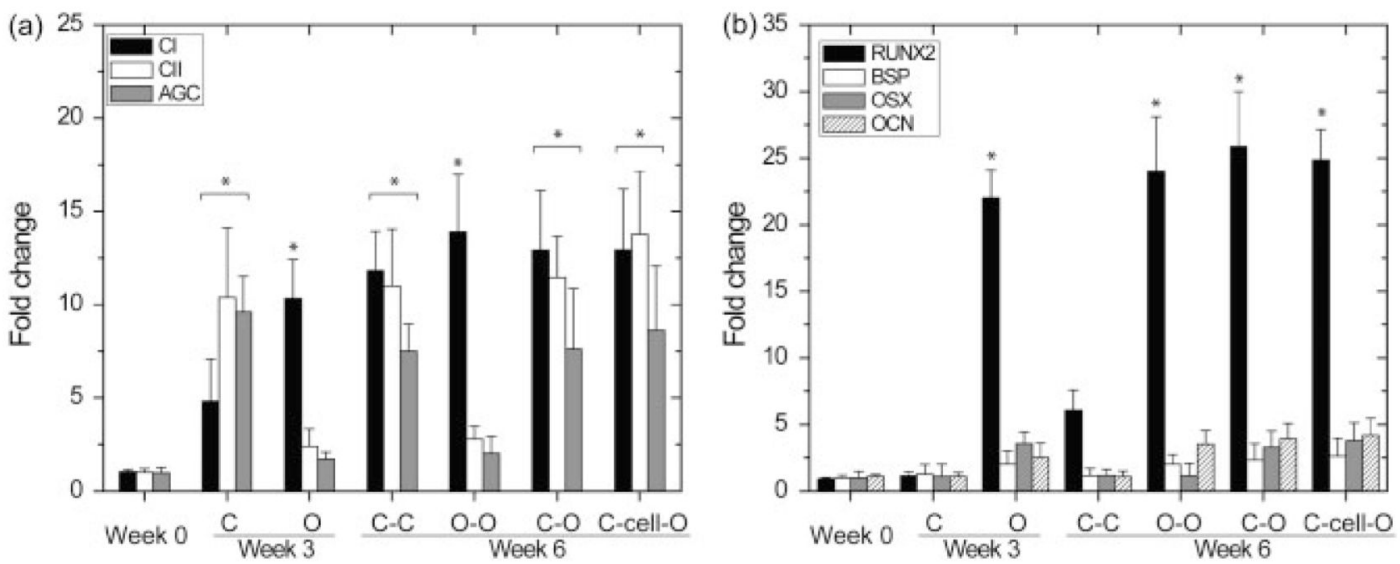

Figure 5.

Gene expression analysis (mean $\pm \mathrm{SD}, n=4$ ). (a) Gene expression of types I and II collagen (CI and $\mathrm{CII}$ ) and aggrecan (AGC) with the constructs at week 0 , chondrogenic (C) and osteogenic $(\mathrm{O})$ constructs at week $3, \mathrm{C}-\mathrm{C}$ and $\mathrm{O}-\mathrm{O}$ composites at week 6 , and the chondrogenic part of the $\mathrm{C}-\mathrm{O}$ and $\mathrm{C}-$-cell-O composites at week 6. (b) Gene expression of runt-related transcription factor 2 (RUNX2), osterix (OSX), bone sialoprotein (BSP) and osteocalcin $(\mathrm{OCN})$ with the constructs at week 0 , chondrogenic $(\mathrm{C})$ and osteogenic $(\mathrm{O})$ constructs at week 3, C-C and $\mathrm{O}-\mathrm{O}$ composites at week 6 , and the osteogenic part of the $\mathrm{C}-$ $\mathrm{O}$ and $\mathrm{C}-$ cell-O composites at week 6 . The increase of $C I I$ and $A G C$ gene expression indicated chondrogenic differentiation of hUCMSCs (a) and the increase of $R U N X 2$ gene expression indicated osteogenic differentiation of hUCMSCs (b). *Statistically significant difference from week 0 